1 Royal College of General Practitioners. Council report. Complaints. Connection 1993 Aug:3.

2 Panting G. How to establish an in house general practice complaints procedure. Medical Protection Society Casebook 1993;2:6-9.

3 Department of Health. Health service indicator 1991-2. London: $\mathrm{DoH}, 1993$.

4 Owen CA. Formal complaints against general practitioners. $\mathrm{Br} f \mathrm{Gen}$ Pract 1991;41:113-5.

5 Stütte $\mathrm{P}$. What the complaints survey means for GPs. London: Medical Defence Union, 1993.

6 Mori Poll Ltd. East London GP services. London: East London Family Health Services Authority, 1993.
7 British Medical Association. Evidence to the NHS Complaints Review Committee. London: BMA, 1993.

8 Medical Defence Union. Coping with patient complaints in general practice. London: MDU, 1993:2.

9 Chase D, Davies $\mathrm{P}$. Calculation of a practice under-privileged area score. $\mathrm{Br} f$ Gen Pract 1991;41:63-6.

10 Pietroni PC, Chase D. Partners or partisans? Patient participation at Marylebone Health Centre (discussion paper). Br $₹$ Gen Pract 1993;43: $341-4$

(Accepted 7 April 1994)

\title{
Cancer Prevention in Primary Care
}

\section{Reducing alcohol intake}

\section{Joan Austoker}

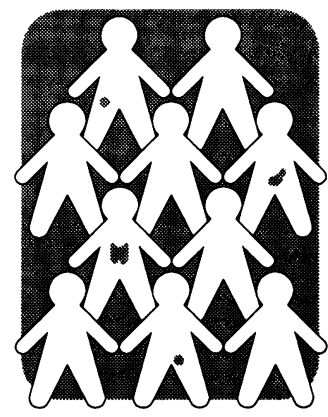

This is the third in a series of articles looking at how cancer can be prevented in general practice

TABLE I-Cancers produced by alcohol consumption

\begin{tabular}{ll}
\hline & Cancer \\
\hline Definitely & Mouth \\
& Pharynx \\
& Larynx \\
& Oesophagus \\
& Liver \\
Possibly & Breast \\
& Rectum \\
\hline
\end{tabular}

^Beer consumption only.

\section{Cancer Research}

Campaign Primary Care

Education Research

Group, Department of

Public Health and Primary

Care, University of Oxford,

Oxford OX2 6PE

Joan Austoker, director

BMF 1994;308:1549-52

\begin{abstract}
Alcohol is second in importance only to smoking as a proved cause of cancer. The risk associated with excessive alcohol consumption can be reduced by adopting national and local population based policies. The population approach is aimed at reducing the level of consumption across the whole population, which contains many modest drinkers. Underlying this approach is the fact that a larger proportion of the total morbidity and mortality attributed to alcohol in a population occurs in modest drinkers, even though individually they are at lower risk. This approach should be complemented by risk reduction initiatives in primary care, focused on high risk individuals. Several studies have shown the efficacy of brief interventions by general practitioners in patients with excessive alcohol consumption. Brief interventions, taking 5 to 10 minutes, use simple assessments to identify those at risk and provide information and advice. Evidence exists that general practitioners underuse opportunities to identify and advise patients about excessive drinking.
\end{abstract}

Alcohol consumption is associated with raised morbidity and mortality. Excessive drinking increases the risk of raised blood pressure and stroke, liver cirrhosis, deaths from accidents, and the development of some cancers. The relation between alcohol and heart disease is complex. Recent research has shown that men who drink up to 30 units of alcohol a week are less likely to die from coronary heart disease than nondrinkers. Any specific protective effect for coronary heart disease, however, is likely to be rapidly offset even at fairly low levels of consumption by the increasing morbidity and mortality from all causes. Alcohol consumption leads to around 28000 deaths each year in England and Wales alone. Eight million working days are estimated to be lost each year through absenteeism related to drinking.

\section{Alcohol and cancer \\ Alcohol is second only in importance to smoking as a proved cause of cancer. Three per cent of all deaths from cancer (around 4300 deaths a year) are related to excess alcohol consumption. In some countries it may be responsible, in conjunction with smoking, for as many as $10 \%$ of all deaths from cancer. The obser- vational evidence that the risks of several types of cancer increase sharply with the amount drunk to more than 10 times that in lifelong non-drinkers, combined with high risks in occupations associated with high consumption, low risks in social groups that abjure alcohol, and reduced risks in ex-drinkers, suggests incontrovertibly that alcohol is carcinogenic in humans.}

Several cancers show evidence of a dose-response relation. Table I shows the types of cancer caused in part by alcohol.

There is strong evidence that alcohol acts synergistically with tobacco. Studies on oral, pharyngeal, and oesophageal cancers have shown that alcohol combines with smoking multiplicatively so that people who smoke and drink heavily have high risks compared with those who neither smoke nor drink (table II). The carcinogenic effects of alcohol may also be synergistic with some aspects of malnutrition. For these cancers, the highest risk is associated with heavy drinkers who also had a low fruit and vegetable intake. Thus the risk of these cancers associated with moderate drinking in well nourished non-smokers is small.

\section{Alcohol consumption}

The overall risk of problems related to alcohol increases continuously with rising consumption. Table III gives an indication of the overall levels of risk in relation to the number of units of alcohol consumed a week. People drinking more than the recommended limits ( $>21$ units a week for men, $>14$ units a week for women) are referred to as hazardous drinkers when they are experiencing no problems as a result of alcohol consumption and as harmful drinkers when they have problems.

TABLE II-Relative risks of oral or pharyngeal cancer in men by alcohol and tobacco consumption

\begin{tabular}{|c|c|c|c|c|c|}
\hline \multirow[b]{2}{*}{ Smoking status } & \multicolumn{5}{|c|}{ No of drinks $\star /$ week } \\
\hline & $<1$ & $1-4$ & $5-14$ & $15-29$ & $\geqslant 30$ \\
\hline Non-smoker & $1 \cdot 0$ & $1 \cdot 3$ & $1 \cdot 6$ & $1 \cdot 4$ & $5 \cdot 8$ \\
\hline $\begin{array}{l}\text { Ex-smoker } \\
\text { Smoker (No of cigarettes/day } \\
\quad \text { for } \geqslant 20 \text { years): }\end{array}$ & $0 \cdot 7$ & $2 \cdot 2$ & $1 \cdot 4$ & $3 \cdot 2$ & $6 \cdot 4$ \\
\hline $1-19$ & $1 \cdot 7$ & 1.5 & $2 \cdot 7$ & $5 \cdot 4$ & $7 \cdot 9$ \\
\hline $20-39$ & 1.9 & $2 \cdot 4$ & $4 \cdot 4$ & $7 \cdot 2$ & $23 \cdot 8$ \\
\hline$\geqslant 40$ & $7 \cdot 4$ & 0.7 & $4 \cdot 4$ & $20 \cdot 2$ & 37.7 \\
\hline
\end{tabular}

*Standard drink in United States, which is 1.5 times the standard drink in United Kingdom. Therefore maximum risk, $\geqslant 30$ drinks/day, is 45 British drinks (units) or $22^{1 / 2}$ pints (13 litres) of beer.

TABLE III-Alcohol consumption by men and women and risk of social and health problems *

\begin{tabular}{|c|c|c|}
\hline \multicolumn{2}{|c|}{$\begin{array}{l}\text { Alcohol intake } \\
\text { (units/week) }\end{array}$} & \multirow{2}{*}{$\begin{array}{l}\text { Risk of problems } \\
\text { Low }\end{array}$} \\
\hline $\begin{array}{l}\text { Men } \\
\text { Women }\end{array}$ & $\begin{array}{l}0-21 \\
0-14\end{array}$ & \\
\hline $\begin{array}{l}\text { Men } \\
\text { Women }\end{array}$ & $\begin{array}{l}22-50 \\
15-35\end{array}$ & $\{$ Increasing, particularly in smokers \\
\hline $\begin{array}{l}\text { Men } \\
\text { Women }\end{array}$ & $\begin{array}{l}>50 \\
>35\end{array}$ & $\{$ High (definitely dangerous); very high in smokers \\
\hline
\end{tabular}

^Adapted from Health of the Nation. ${ }^{3}$ 
Alcohol consumption doubled in the United Kingdom between the 1950s and late 1970s, after which consumption dropped slightly and has remained at around 9 litres of pure alcohol per annum per person aged 15 and over. At the same time the price of alcoholic drinks has been falling in real terms so that it is now just over half of what it was in the 1950s.

In 1992 men aged $\geqslant 18$ in the United Kingdom drank on average 15.9 units of alcohol a week (about 8 pints of beer or the equivalent), which is about three times a much as women drank (5.4 units on average). Twenty seven per cent of men and $11 \%$ of women drink more than the recommended limits, with $6 \%$ of men and $2 \%$ of women drinking in excess of 50 units a week. Young adults drink the most-38\% of men and $18 \%$ of women aged 18-24 drink more than the recommended limits. Patterns of drinking vary considerably between people-for example, for cultural reasons. Alcohol consumption is highest among young adults.

\section{Strategies for promoting sensible drinking and reducing alcohol misuse}

There are several approaches for reducing alcohol related problems in the population. The high risk approach, on the one hand, is concerned with identifying and helping the few with special problems by treating their risk factors or seeking changes in their behaviour. The population approach on the other hand, is aimed at reducing the level of consumption across the whole population, which contains many modest drinkers. Underlying this approach is the fact that a larger proportion of the total morbidity and mortality attributable to alcohol in a population occurs in modest drinkers, even though individually they are at lower risk. These two approaches are not incompatible, in that it has been argued that the population mean predicts the prevalence of rates of high alcohol consumption. Thus a fall in mean alcohol consumption may lead to a corresponding decrease in the number of very heavy drinkers. Alcohol consumption can be reduced in the population by increasing tax on alcohol, advertising controls, drink-driving campaigns, occupational health strategies in the workplace, and limiting or controlling the availability of alcohol through the licensing laws. National policy needs to be supported by effective local action.

Any policy for reducing alcohol consumption will have to acknowledge the fact that the consumption of alcohol has been common for centuries and is regarded by many as pleasurable. The key challenge is to devise a strategy that realistically takes into account health, economic, social, and cultural factors and increases the understanding that the potential for health and social gain from reduced drinking is large.

Box 1 shows the target for reducing alcohol consumption in the Health of the Nation. Concerted action will be required nationally and locally to tackle the problems connected with excessive and inappropriate consumption. The Health of the Nation strategy requires interagency collaboration at all levels from the NHS to schools and the voluntary sector, as well as the use of appropriate health education materials.

\section{Box 1-Health of the Nation target for alcohol $^{3}$}

To reduce the proportion of men drinking more than 21 units of alcohol per week from $28 \%$ in 1990 to $18 \%$ by 2005 , and the proportion of women drinking more than 14 units of alcohol per week from $11 \%$ in 1990 to $7 \%$ by 2005
Although the population approach is likely to achieve the greatest overall effect, measures that greatly benefit the population as a whole offer little to each individual participant and may result in poor motivation to reduce drinking. A high risk strategy, based on primary health care, is thus needed to complement a population based approach. Primary care is an important setting for identifying people at risk of heavy drinking and helping them to reduce consumption. Heavy drinkers consult their general practitioners twice as often as lighter drinkers, emphasising the potential for opportunistic interventions in general practice to target those most at risk.

As part of the Health of the Nation strategy related to alcohol consumption, primary care teams are being encouraged to identify the scope for health promotion initiatives. Included in band 3 of the new primary care health promotion programme is the requirement for general practitioners to collect information on alcohol and, when appropriate, offer advice on lifestyle as well as some form of intervention and follow up. Table IV sets out the levels of alcohol consumption where intervention is recommended in primary care.

TABLE IV-Alcohol intake by men and women and recommended intervention in primary care ${ }^{\star}$

Alcohol intake

(units/week)

Intervention

$\begin{array}{ll}\text { Men } & 0-21 \\ \text { Women } & 0-14\end{array}\{$ None-reasonable limits for most adults

Men 22-35

Women 15-21 Keep patients under review

Men $>35$ Advise to cut down; implement an alcohol reduction Women $>21 \quad\left\{\begin{array}{l}\text { Advise } \\ \text { strategy }\end{array}\right.$

*Adapted from Anderson. ${ }^{4}$

\section{Identifying those at risk}

Several methods have been used to identify those at risk, including asking questions about consumption, keeping diaries of drinking, questionnaires, physical examination, and measuring biological markers. These have been used alone or in combination. In general, almost all of these instruments were developed to detect alcohol dependency in patients in hospital and not to screen for lower levels of consumption or to detect those at risk in other settings such as primary care.

Practical screening measures are available for use in primary care. The use of a screening instrument in primary care can lead to substantial improvements in the identification of people with alcohol problemsin one practice there was an $80 \%$ increase in the number of patients identified. The World Health Organisation has developed a simple method to screen for people with early signs of alcohol related problems in general practice (the AUDIT questionnaire). It still needs to be validated for use in the United Kingdom. The importance of screening in primary care for alcohol consumption is emphasised by the fact that people drinking in excess of the recommended limits form up to $20 \%$ of patients presenting to general practitioners. Yet in a study of 2288 self identified heavy drinkers, only $28 \%$ were correctly identified as being at risk by their general practitioner. In addition, screening programmes have not been extensively undertaken in general practice to date.

\section{How effective are brief interventions?}

Various trials of brief interventions have been conducted. Brief interventions consisting of assessment of intake and provision of information and advice significantly reduce alcohol consumption by over a 
fifth in the large group of people with raised alcohol consumption. How this relates into changes in health, however, is not clear. The trials have used various outcome measures. Few have directly measured health related outcomes, and most use patients' reported changes in alcohol consumption as the primary outcome measure. The reliability of self reported changes in behaviour is, however, doubtful. In addition, to estimate the longer term impact on health status using trial data is difficult because follow up is short. Also, trials include patients whose consumption is considerably above the Health of the Nation targets, and it is unclear to what extent the findings in such patients can be translated to people in the general population whose drinking is above target levels.

Some evidence suggests that brief interventions are as effective as more expensive specialist treatments. This makes brief interventions the most strongly supported method of intervention for alcohol problems and, certainly, the most cost effective. When brief interventions are unsuccessful more specialist interventions may prove effective, but further research is required.

\section{How effective are general practitioners in reducing consumption?}

Research to date provides support for the efficacy of brief interventions in primary care. Six studies have been published on the effectiveness of brief interventions by general practitioners in patients with excessive alcohol consumption. The results of studies with adequate sample sizes suggest that between 5 minutes and 10 minutes of simple advice from a general practitioner plus a leaflet led to around a $25-35 \%$ reduction in drinking at follow up six months or one year later and to around a $45 \%$ reduction in the proportion of excessive drinkers. There was greater evidence for an effect of intervention among men than women. In one study a greater investment of the general practitioners' time through repeat visits led to improved outcomes. The dose response effect may be due to a synergistic effect of repeated visits as well as greater motivation of the patients who chose to return to their general practitioner. The studies provide some understanding of the effective components of brief interventions (box 2). Care should be taken, however,

\section{Box 2-Effective components of brief interventions ${ }^{\star}$}

- The target should be a reduction in the consumption itself

- There is little evidence to suggest that an intervention including condensed cognitive behavioural therapy and the use of self help manuals and follow up visits is superior to those including 5-10 minutes of simple advice from a general practitioner and a leaflet

- Incorporating the principles of the process of change model and the techniques of motivational interviewing may lead to improved outcomes

- Age, socioeconomic status, and marital status do not seem to predict outcome

- Initial level of consumption may predict outcome, whereby heavier drinkers reduce their alcohol consumption by a significantly greater amount than lighter drinkers

- The effect of a minimal intervention is enhanced when a patient has experienced a recent problem caused by alcohol

- Sex specific intervention strategies need to be evaluated

*Adapted from Anderson
Box 3-Brief interventions: key issues for primary care teams

- Assess alcohol intake

- Identify problem drinkers and people at risk

- Recognise the synergistic effects: are people smoking as well?

- Target those whose consumption is high

- Use intervention in men who drink $>35$ units a week and women who drink $>21$ units a week

- Provide brief advice and information specific to each patient

- Inform patients about sensible levels in units of alcohol: for men $\leqslant 21$ units a week and for women $\leqslant 14$ units a week

- Give appropriate health education literature

- Agree on action plan

- Plan follow up action

- Consider referral when appropriate

in extrapolating research findings to general practice in general. Only a small proportion of patients are recruited for research, and the sample may not be representative of the entire general practice population.

Box 3 shows the key issues for inclusion in a brief intervention in primary care. Little information is currently available on the best methods of dissemination of brief interventions for excessive drinkers in general practice, but much can be learnt from the methods used to implement interventions for stopping smoking. Smoking cessation research has shown that trained practitioners have higher success rates than untrained practitioners and that continuing training and support lead to a higher rate of compliance among practitioners, with continued participation in preventive programmes.

\section{Conclusions}

Alcohol is an important cause of death, including deaths related to cancer, and ill health in the United Kingdom. The risk associated with excessive alcohol consumption can be reduced by adopting national and local population based policies. These should be complemented by risk reduction initiatives based in primary care, which entail the opportunistic use of simple assessments to identify those at risk and brief interventions carried out routinely. Brief advice from general practitioners leads to a reduction in drinking generally of $25-35 \%$ and is cost effective to implement. Although general practitioners can have a potential impact on the lifestyles of their patients, they underutilise opportunities to identify and advise patients about excessive drinking. Many doctors are reluctant to intervene in helping to reduce their patients' drinking. A study in 1985 found that only $40 \%$ felt motivated to work with excessive drinkers. In a recent survey of 5000 adults only $2 \%$ reported discussing drinking with their general practitioner or any member of the practice staff during the previous 12 months.

Despite the results of the trials conducted in general practice, there are several barriers to implementing the available interventions, including lack of training and support. Success rates from even the most effective interventions are low, so general practitioners do not receive adequate positive reinforcement for their efforts with patients. Repeated failures with patients can affect the confidence and motivation of general practitioners, and may work against them continuing to use these interventions. In applying brief interventions general practitioners should be provided with appropriate health education material. If the interventions 
are successful doctors may then be prepared to invest more time in them. Further consideration should be given to new ways that general practitioners can deliver and follow up lifestyle interventions, including implementing the process of change model and undertaking motivational interviewing. The role of practice nurses, health visitors, and specialist clinics may be important in enhancing a general practitioner's initial intervention.

I am grateful to Dr Peter Anderson for commenting on a draft of this article.

1 Blot W. Alcohol and cancer. Cancer Res 1992;52 (suppl):2119-23S

2 Cancer Research Campaign. Factsheet 14: oral cancer. London: CRC, 1993.

3 Secretary of State for Health. Health of the Nation: a strategy for health in England. London: HMSO, 1992. (Cm 1986.)

4 Anderson P. Reducing alcohol consumption. In: Fowler G, Anderson P, Gray $M$, eds. Prevention in general practice. Oxford: Oxford University Press, 1993:136-47.

5 Anderson P. Effectiveness of general practice interventions for patients with harmful alcohol consumption. $B r$ f Gen Pract 1993;43:386-9.

\section{Selected additional references}

Anderson P. Alcohol as a key area. BMf 1991;303:766-9.

Anderson P. The interaction between research and policy-alcohol and general practice in the United Kingdom. Addiction 1993;88:1215-75.

Anderson P. Population and high-risk approaches both necessary to reduce population harm. Addiction 1993;88:170-4.

Anderson P, Cremona A, Paton A, Turner C, Wallace P. The risk of alcohol. Addiction 1993;88:1493-508.

Anderson P, Wallace P, Jones H. Alcohol problems: practical guides for general practice. Oxford: Oxford University Press, 1988.

Andserson P, Scott $E$. The effect of general practitioners advice to heavy drinking men. Brf Addict 1992;87:891-900.

Babor TF, Grant M. WHO Collaborating Investigators Project on identification and management of alcohol related problems. Combined analyses of outcome data: the cross national generalizability of brief interventions. Report on phase II: a randomised cross national generalizability of brief interventions. Repon on phase II: a
clinical trial of brief interventions in primary care. Copenhagen: WHO, 1992.

Bien TH, Miller WR, Tonigan JS. Brief interventions for alcohol problems: Bien TH, Miller WR, Tonigan
review. Addiction 1993;88:315-36.
Doll R. The prevention of cancer: opportunities and challenges. In: Heller T, Davey B, Bailey L, eds. Reducing the risk of cancers. London: Hodder and Stoughton, 1989:14-25.

Effective Health Care. Brief interventions and alcohol use. Nuffield Institute for Health, University of Leeds; Centre for Health Economics, University of York; Research Unit, Royal College of Physicians, 1993.

Health Education Authority. Cut down on your drinking pack. London: HEA, 1991.

International Agency for Research on Cancer. IARC monographs on the evaluation of carcinogenic risks to humans: alcohol drinking. Lyons: IARC, 1988.

Medical Council on Alcoholism. Hazardous drinking: a handbook for general practitioners London: MCA, 1987.

Office of Population Censuses and Surveys. General household survey 1992. London: HMSO, 1994.

Prochaska J, DiClemente C. Toward a comprehensive model of change. In: Miller WR, Heather N, eds. Treating addictive behaviors: processes of change. New York: Plenum, 1986:3-27.

Rollnick S, Heather N, Gold R, Hall W. Development of a short "readiness to change" questionnaire for use in brief, opportunistic interventions among excessive drinkers. Br F Addiction 1992;87:743-54.

Royal College of General Practitioners. Alcohol-a balanced view. London: RCGP, 1986.

Royal College of General Practitioners. Alcohol and drugs. London: RCGP, 1991

Royal College of Physicians. The medical consequences of alcohol abuse: a great and rowing evil. London: Tavistock, 1987.

Reid ALA, Webb GR, Hennrikus D, Fahey PP, Sanson-Fisher RW. Detection of patients with high alcohol intake by general practitioners. BMF 1986;293: 735-7.

Rose G, Day S. The population mean predicts the number of deviant individuals. $B M 7$ 1990;301:1031-4.

Saunders JB, Aasland OG, Babor TF, De La Fuente JR, Grant M. Development of the alcohol use disorders identification test (AUDIT): WHO Collaborative Project on Early Detection of Persons with Harmful Alcohol Consumption-II. Addiction 1993;88:791-804.

Scott E, Anderson P. Randomised controlled trial of general practitioners intervention in women with excessive alcohol consumption. Drug and Alcohol Review 1990;10:313-2.

Wallace P, Cutler S, Haines A. Randomised controlled trial of general practitioners intervention in patients with excessive alcohol consumption. $B M F$ 1988;297:663-8.

Wallace $P$, Haines $A$. The use of a questionnaire in general practice to increase the recognition of patients with excessive alcohol consumption. $B M 71985 ; 290$ : 1949-53.

A complete list of references can be obtained from the author

\title{
Statistics Notes
}

\section{Diagnostic tests 1: sensitivity and specificity}

\author{
Douglas G Altman, J Martin Bland
}

This is the third in a series of occasional notes on medical statistics.

\section{Medical Statistics Laboratory, Imperial Cancer Research Fund, London WC2A 3PX Douglas G Altman, head}

Department of Public Health Sciences, St George's Hospital Medical School, London SW17 0RE

J Martin Bland, reader in medical statistics

$B M \Im 1994 ; 308: 155$
The simplest diagnostic test is one where the results of an investigation, such as an $x$ ray examination or biopsy, are used to classify patients into two groups according to the presence or absence of a symptom or sign. For example, the table shows the relation between the results of a test, a liver scan, and the correct diagnosis based on either necropsy, biopsy, or surgical inspection. ${ }^{1}$ How good is the liver scan at diagnosis of abnormal pathology?

Relation between results of liver scan and correct diagnosis ${ }^{t}$

\begin{tabular}{lccc}
\hline & \multicolumn{3}{c}{ Pathology } \\
\cline { 2 - 4 } Liver scan & $\begin{array}{c}\text { Abnormal } \\
(+)\end{array}$ & $\begin{array}{c}\text { Normal } \\
(-)\end{array}$ & Total \\
\hline Abnormal (+) & 231 & 32 & 263 \\
Normal (-) & 27 & 54 & 81 \\
\hline Total & 258 & 86 & 344 \\
\hline
\end{tabular}

One approach is to calculate the proportions of patients with normal and abnormal liver scans who are correctly "diagnosed" by the scan. The terms positive and negative are used to refer to the presence or absence of the condition of interest, here abnormal pathology. Thus there are 258 true positives and 86 true negatives. The proportions of these two groups that were correctly diagnosed by the scan were $231 / 258=0.90$ and $54 / 86=0.63$ respectively. These two proportions have confusingly similar names.

Sensitivity is the proportion of true positives that are correctly identified by the test.

Specificity is the proportion of true negatives that are correctly identified by the test.

We can thus say that, based on the sample studied, we would expect $90 \%$ of patients with abnormal pathology to have abnormal (positive) liver scans, while $63 \%$ of those with normal pathology would have normal (negative) liver scans.

The sensitivity and specificity are proportions, so confidence intervals can be calculated for them using standard methods for proportions. ${ }^{2}$

Sensitivity and specificity are one approach to quantifying the diagnostic ability of the test. In clinical practice, however, the test result is all that is known, so we want to know how good the test is at predicting abnormality. In other words, what proportion of patients with abnormal test results are truly abnormal? This question is addressed in a subsequent note.

\footnotetext{
1 Drum DE, Christacapoulos JS. Hepatic scintigraphy in clinical decision making. $f$ Nucl Med 1972;13:908-15.

2 Gardner MJ, Altman DG. Calculating confidence intervals for proportions and their differences. In: Gardner MJ, Altman DG, eds. Statistics with confidence.
} London: BMJ Publishing Group, 1989: 28-33. 